\title{
O PATRIMÔNIO ARQUITETÔNICO DE SOROCABA VISTO ATRAVÉS DO ACERVO FOTOGRÁFICO DO IPHAN
}

CLAUDIA DOS REIS E CUNHA UNIVERSIDADE FEDERAL DE UBERLÂNDIA, UBERLÂNDIA, MINAS GERAIS, BRASIL

Arquiteta e especialista em História e Cultura pela Universidade Metodista de Piracicaba, mestre e doutora em História e Fundamentos da Arquitetura e do Urbanismo pela Faculdade de Arquitetura e Urbanismo da Universidade de São Paulo. Professora doutora na Faculdade de Arquitetura e Urbanismo e Design da Universidade Federal de Uberlândia.

E-mail: claudiareis@ufu.br

DOI

http://dx.doi.org/10.11606/issn.1980-4466.v13i25esp25p135-162 


\section{O PATRIMÔNIO ARQUITETÔNICO \\ DE SOROCABA VISTO ATRAVÉS DO ACERVO FOTOGRÁFICO DO IPHAN ${ }^{1}$}

CLAUDIA DOS REIS E CUNHA

\section{RESUMO}

Este artigo apresenta parte dos resultados da pesquisa "O patrimônio cultural da cidade de Sorocaba: análise de uma trajetória”, desenvolvida na Faculdade de Arquitetura e Urbanismo da Universidade de São Paulo, no que se refere especificamente aos procedimentos de inventário e consequente atribuição de valor aos bens culturais da cidade de Sorocaba-SP empreendidos pelo Instituto do Patrimônio Histórico e Artístico Nacional (Iphan), tendo como principal base documental utilizada o acervo fotográfico da

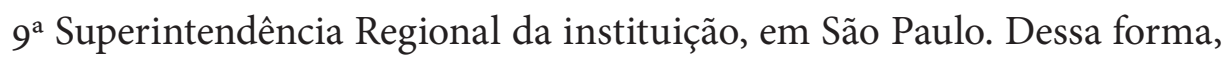
procura-se problematizar as ações do órgão federal de preservação no que se refere ao município de Sorocaba, os critérios e procedimentos adotados, privilegiando o papel que o documento fotográfico teve na construção de uma narrativa visual daquilo que era - ou não - importante como memória a ser transmitida às gerações posteriores.

\section{PALAVRAS-CHAVE}

Patrimônio arquitetônico - Sorocaba (SP). Fotografia. Memória cultual. Instituto do Patrimônio Histórico e Artístico Nacional - Iphan.

\footnotetext{
1. Este artigo apresenta resultados obtidos durante a pesquisa de mestrado desenvolvida na Faculdade de Arquitetura e Urbanismo da Universidade de São Paulo (FAU-USP) entre os anos 2003-2005, intitulada "O patrimônio cultural de Sorocaba: análise de uma trajetória", a qual contou com a orientação da profa. dra. Beatriz Mugayar Kühl e o apoio financeiro do Conselho Nacional de Pesquisa Científicas (CNPq).
} 


\section{THE ARCHITECTURAL HERITAGE OF SOROCABA SEEN THROUGH THE IPHAN PHOTOGRAPHIC COLLECTION \\ CLAUDIA DOS REIS E CUNHA}

\section{ABSTRACT}

This article presents part of the results of the research "The cultural heritage of the city of Sorocaba: an analysis of a trajectory", developed at the FAU-USP, specifically regarding the inventory procedures and consequent value attribution to the cultural assets of the city of Sorocaba-SP undertaken by the National Historical and Artistic Heritage Institute (Iphan), having as main documentary base the photographic collection of the 9th Regional Superintendence of the institution, in São Paulo. In this way, we try to problematize the actions of the federal preservation agency regarding the city of Sorocaba, the criteria and procedures adopted, privileging the role that the photographic document had in constructing a visual narrative of what it was - or not important as memory to be passed on to later generations.

\section{KEYWORDS}

Architectural heritage - Sorocaba (SP). Photography. Memory. Patrimônio Histórico e Artístico Nacional - Iphan 


\section{O IPHAN E A FOTOGRAFIA DOS BENS CULTURAIS}

Neste século XXI vivencia-se uma banalização da imagem. Multiplicaramse enormemente os meios de produção e reprodução das imagens, bem como seus suportes. O cotidiano é cercado e mesmo bombardeado por uma avalanche de informações visuais a todo momento. Ao mesmo tempo fundamental para a construção das identidades, como registro de si e dos acontecimentos, as imagens muitas vezes são tratadas - no horizonte da cultura de massas - como mais um item descartável de consumo, carecendo de maiores análises seja em seus usos, seja em seus significados.

A despeito de uma crescente importância dada desde os anos 1980 aos estudos da chamada cultura visual no âmbito dos mais diversos campos disciplinares (MENESES, 2003, p. 23), pode-se, neste cotidiano invadido pela imagem, negligenciar os grandes esforços necessários e que foram empreendidos, desde o final do século XIX e nas primeiras décadas do século $\mathrm{XX}$, para dotar organizações públicas e privadas de um acervo visual - em especial de fotografias - a fim de documentar suas atividades.

No tocante ao patrimônio cultural, várias foram as instituições ao redor do mundo que adotaram os registros visuais como meio privilegiado de registrar os bens culturais e artísticos, ganhando destaque o aspecto de "documento científico" que o registro fotográfico tinha para aquelas. A Carta de Atenas, primeiro documento internacional a tematizar a 
conservação dos bens culturais, de 1931, já recomendava o uso da fotografia como parte integrante da documentação dos inventários de bens culturais (IPHAN, 200o, p. 17). Como afirma Costa (2016, p. 26):

Na virada do século XIX para o XX, a fotografia passou a ocupar um lugar decisivo na manutenção de balizas legíveis e compartilhadas por toda a comunidade de investigadores ligados às artes, fazendo dessas instituições centros de referência para as investigações ligadas à fotografia. Já no campo do patrimônio, a relação estabelecida com a fotografia surge desde a invenção desse meio de representação, utilizado precocemente para documentar monumentos, o que realçava o caráter científico desse suporte documental.

No caso do Instituto do Patrimônio Histórico e Artístico Nacional (Iphan)², desde seu surgimento, há 80 anos, a questão da formação do acervo fotográfico estava posta como necessidade premente, dado que é considerada fundamental para complementar a documentação nos inventários a serem executados pelos técnicos do órgão, assim como para registrar o estado de conservação e as obras executadas nos bens já acautelados. A despeito dos parcos recursos desde sempre destinados ao funcionamento do órgão federal de preservação, o Iphan dedicou esforços para a contratação de fotógrafos profissionais que pudessem executar "documentação fotográfica tão completa quanto possível”, conforme destacava Rodrigo Melo Franco de Andrade a Godofredo Filho, em carta escrita ainda no ano de 1937 (FONSECA; CERQUEIRA, 2008, p. 14). Mesmo antes da oficialização das atividades da instituição, a documentação dos bens culturais brasileiros através do suporte fotográfico já era assunto de amplas discussões, como

\footnotetext{
2. Ao longo de seus 80 anos de existência, o Iphan sofreu diversas alterações dentro da estrutura burocrática federal, o que acarretou mudanças na figura jurídica e no nome do órgão. Em 1946, o antigo Serviço do Patrimônio Histórico e Artístico Nacional (SPHAN) foi transformado em Diretoria, sob a sigla DPHAN. Em 1970 transformou-se em Instituto do Patrimônio Histórico e Artístico Nacional (Iphan), passando a Secretaria em 1979, novamente com a sigla SPHAN. A partir de 1981, mesmo mantendo a sigla, a instituição tornou-se subsecretaria, e, em 1990, transformou-se em Instituto Brasileiro de Patrimônio Cultural (IBPC), voltando em 1994 a denominar-se Instituto do Patrimônio Histórico e Artístico Nacional (Iphan), sua designação atual e que será aqui adotada ao longo de todo o trabalho, independentemente da época à qual se refira.
} 
pode ser atestado pela correspondência entre Rodrigo Melo Franco de Andrade e Mário de Andrade (COSTA, 2016, p. 15).

Logo após o início das atividades do IPHAN, o trabalho de documentação e organização de um Arquivo Fotográfico ganhou forma através das pesquisas, levantamentos e restauros das edificações tombadas. Desde o primeiro ano, a importância do papel da fotografia aparece assinalada através de muitos debates, trabalhos e publicações, como a própria Revista do Patrimônio, bem como pelo volume de documentos fotográficos incorporados pela diretoria no Rio de Janeiro. Percebe-se, assim, que este meio de documentação do patrimônio e, consequentemente, a formação de um referencial imagético foram atividades importantes no processo cotidiano dos trabalhos. Tratava-se, portanto, de peça chave na estruturação deste Instituto (COSTA, 2015, p. 115).

Compreendendo a importância do acervo fotográfico do Iphan como meio privilegiado na construção de um discurso sobre a memória brasileira, na medida em que consolidavam uma dada forma de ver aquilo que era considerado meritório na visão dos técnicos da instituição, este trabalho se propõe a lançar alguns olhares sobre uma pequena parcela do acervo fotográfico do Instituto do Patrimônio Histórico e Artístico Nacional (Iphan), tendo em perspectiva o valor deste acervo não apenas para uma história da preservação no Brasil, mas como documentação de um determinado olhar sobre os bens culturais cristalizado nessas fotografias, acreditando que

As fotografias produzidas, mais do que instrumentos de trabalho, articulavam-se às concepções patrimoniais existentes e, assim, constituíam um olhar específico sobre objetos artísticos, edificações, cidades e paisagens (FONSECA; CERQUEIRA, 2008, p. 13-14).

O que se propõe com este artigo é apresentar parte dos resultados obtidos na pesquisa de mestrado desenvolvida na FAU-USP intitulada "O patrimônio cultural da cidade de Sorocaba: análise de uma trajetória" no que se refere especificamente aos procedimentos de inventário e consequente atribuição 
de valor aos bens culturais do município de Sorocaba-SP empreendido pelo Iphan, tendo como principal base documental utilizada o acervo fotográfico de sua $9^{a}$ Superintendência Regional (9a SR/Iphan), em São Paulo. Dessa forma, procura-se problematizar as ações do órgão federal de preservação no que se refere a essa cidade do interior paulista, os critérios e procedimentos adotados, privilegiando o papel que o documento fotográfico teve na construção de uma narrativa visual daquilo que era - ou não - importante como memória a ser transmitida às gerações posteriores.

\section{A ATUAÇÃO DO IPHAN EM SOROCABA}

A cidade de Sorocaba aparece no "mapa"3 do Iphan já em 1937, integrando um conjunto de cidades do interior paulista visitadas por Mário de Andrade, na qualidade de assistente técnico do Iphan. Em seu primeiro relatório enviado ao diretor-geral do órgão, Rodrigo M. F. de Andrade, Mário menciona visitas a

S. Roque, Cotia, Itaquaquecetuba, MBoy, Votoruna, Sto. Amaro, S. Miguel, Itu, Porto Feliz, Sorocaba, S. Luís do Paraitinga, Ubatuba, Parnaíba, Pirapora, Barueri, Cabreúva, Atibaia, Perdões e Biacica (ANDRADE, 1981, p. 80).

O trabalho realizado pelo assistente técnico se caracterizou, substancialmente, pelo levantamento fotográfico, no qual se buscava registrar preliminarmente aqueles bens que pudessem ser representativos do caráter nacional e que se apresentassem, em atendimento aos pressupostos do Decreto-lei n. 25/37, como "restos qualificados para receber a proteção do poder público" (SAIA, 1978, p. 8). As fotografias muitas vezes se resumiam a uma única tomada de cada edificação, que seria depois revisitada no caso de um estudo mais aprofundado, que visasse ao tombamento. Como destacam Fonseca e Cerqueira (2008, p. 24):

Muitos tombamentos eram feitos baseados na análise destas fotografias, dada a dificuldade de acesso às diversas localidades do Brasil e, por vezes, às limitações financeiras, que impediam os técnicos de irem a campo. Daí a importância

3. Para retomar uma expressão de Silvana Rubino (RUBINO, 1996, p. 96-105). 
da prática fotográfica naquele momento, funcionando como um instrumento que aproximava dos técnicos do SPHAN os bens arquitetônicos encontrados no Brasil, a serem tombados ou restaurados.

No caso de Sorocaba, conforme se verá detalhadamente mais adiante, embora tenham sido visitadas e fotografadas inúmeras edificações na cidade ainda nesses primeiros anos de funcionamento do Iphan, no item "Itu, Porto Feliz e Sorocaba" de seu primeiro relatório, Mário de Andrade destaca apenas as igrejas de Santo Antônio e Santa Clara, além do Mosteiro de São Bento, cuja "ausência do bispo e do prior [...] impediram se fotografasse este edifício e a obtenção de dados históricos, de que o sr. bispo é abundante" (ANDRADE, 1981, p. 102-103). Seu parecer sobre Porto Feliz pode ser indicativo da tônica de suas impressões sobre a região: "sendo sempre certo que nada mais chamou a atenção dos pesquisadores, por qualquer maior importância, para este Serviço" (ANDRADE, 1981, p. 102).

O resultado do trabalho de inventário no município de Sorocaba empreendido pelos técnicos do Iphan desde 1937 foi apenas uma única inscrição no Livro de Tombo Histórico, datada de 1964 - portanto quase 30 anos após as primeiras visitas dos técnicos do Patrimônio -, correspondente aos remanescentes da Real Fábrica de Ferro São João de Ipanema, primeira iniciativa brasileira na área da siderurgia. A maior parte dos edifícios inventariados pelos agentes do Patrimônio Nacional já não mais existe, ainda que alguns permaneçam no tecido urbano e, inclusive, sejam reconhecidos oficialmente como patrimônio estadual ou municipal.

\section{CARACTERIZAÇÃO DO INVENTÁRIO FOTOGRÁFICO DO IPHAN RELATIVO A SOROCABA}

O inventário fotográfico dos bens da região de Sorocaba feito pelos técnicos

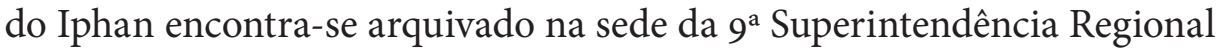
do órgão, sediada na cidade de São Paulo4. Na pesquisa feita aos arquivos

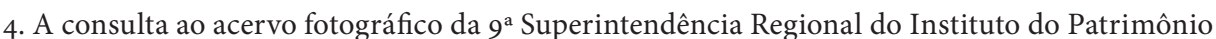
Histórico e Artístico Nacional, na cidade de São Paulo, foi feita a partir do mês de fevereiro de 2004, oportunidade em que se travou contato com a responsável pelo acervo, a fotógrafa Anita Miriam Hirschbruch, a quem a autora agradece a atenção dispensada. A visita à instituição foi feita no início de abril de 2004.
} 
institucionais sobre bens do município de Sorocaba, foram encontradas, no total, 20 obras de arquitetura registradas (Quadro 1). Na maioria dos casos a documentação era restrita a uma única tomada fotográfica para cada edificação.

O montante de fotografias encontrado na repartição cobre um arco temporal que se estende de 1937 a 1949 - relativo especificamente ao trabalho de inventário -, existindo, ademais, a documentação das obras de restauração executadas pelo Iphan na Fazenda Ipanema, que se estendem, por sua vez, de 1968 a 1978. Os primeiros bens inventariados foram o Convento de Santa Clara e a Igreja de Santo Antônio (fotografias de Hugo Graeser, o Germano, de outubro de 1937), bens que constam no relatório de Mário de Andrade. Alguns anos mais tarde foi feito o levantamento fotográfico do Mosteiro de São Bento (também feito por Germano, datado de julho de 1940), que à ocasião não pôde ser fotografado, como relata Mário.

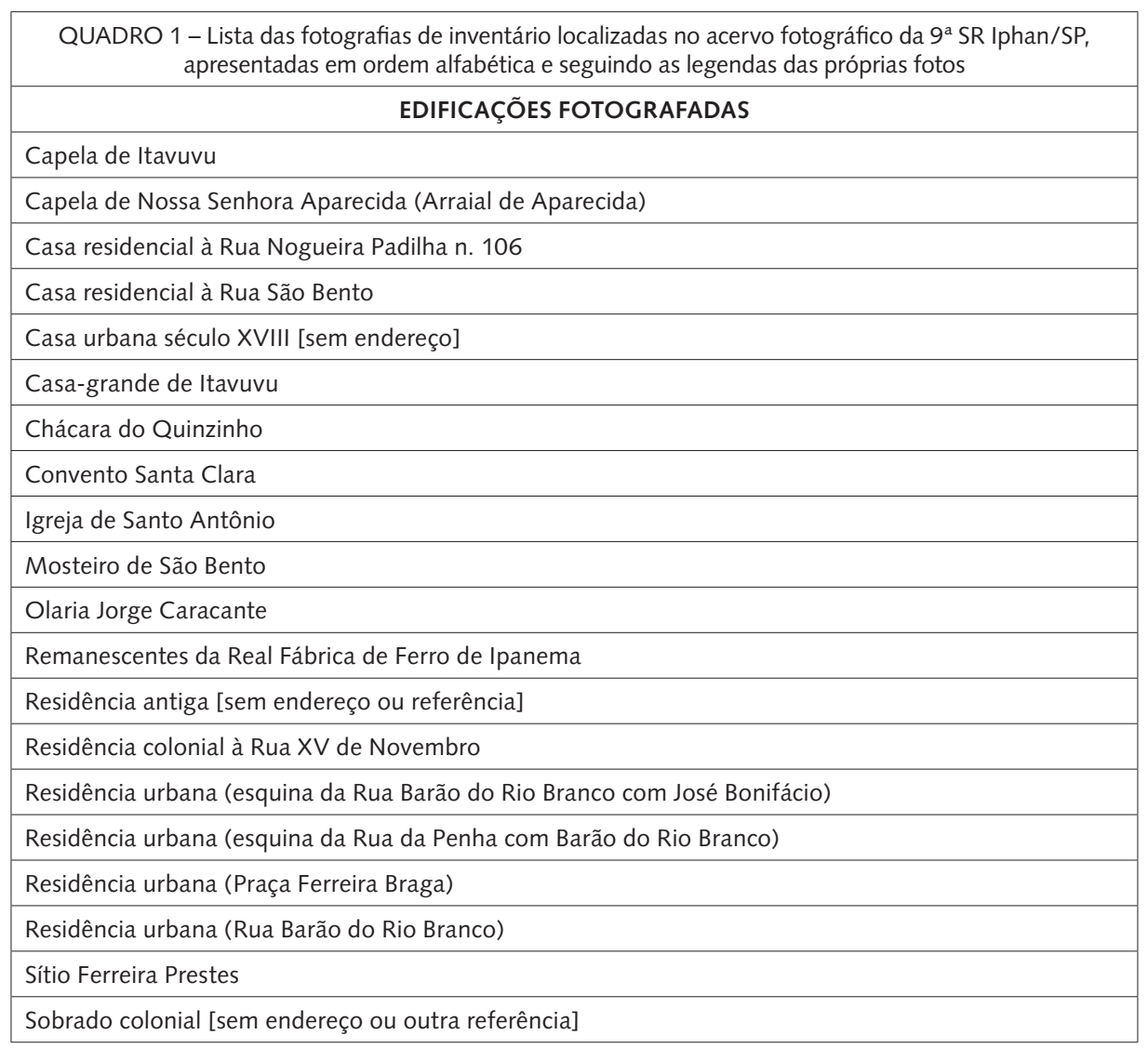


Os bens arquitetônicos documentados são de tipologias variadas, incluindo diversas igrejas, algumas capelas rurais, várias residências urbanas e também casas rurais. Em comum entre os diferentes edifícios registrados é a época de construção, a qual se concentra no período colonial, estendendo-se desde a fundação da cidade, em meados do século XVII, até a primeira metade do século XIX. Não há nenhum registro, entre as fotografias encontradas, de construções edificadas em época posterior, seja da segunda metade do século XIX, seja do século XX.

Dado o maior número de tomadas fotográficas, pode-se afirmar que as edificações que despertaram maior interesse foram: o Mosteiro de São Bento, o Convento de Santa Clara e a Igreja de Santo Antônio, todos monumentos localizados no núcleo primitivo da vila fundada por Baltazar Fernandes; residência implantada na altura do número 106 da Rua Nogueira Padilha, um pouco mais distante da área central, mas ainda pertencente ao perímetro urbanizado da cidade neste primeiro período; a Chácara do Quinzinho, a casa-grande de Itavuvu, bem como a Olaria Jorge Caracante (suposta casa do fundador da cidade, o bandeirante Baltazar Fernandes), todas localizadas na zona rural; as capelas rurais de Nossa Senhora Aparecida e de Itavuvu; e, finalmente, a Fábrica de Ferro São João de Ipanema.

Como não foi possível fotografar o Mosteiro de São Bento na primeira visita de Mário de Andrade, em 1937, ele foi registrado por Germano em 1940. O acervo documental é composto por fotografias externas (Figura 1) e internas da edificação, que incluem a nave, a capela-mor e o coro da Igreja de Santa Ana (contígua ao Mosteiro, e por isso popularmente conhecida como Igreja de São Bento), o claustro e seus corredores, além de detalhes decorativos, tais como as talhas dos altares e as pinturas em tela da Igreja, e detalhes construtivos, como a torre e a portada principal.

Remanescente do período de constituição da Vila de Nossa Senhora da Ponte de Sorocaba, o conjunto formado pelo Mosteiro de São Bento e a Igreja de Santa Ana data da segunda metade do século XVII. Construída a partir da antiga capela de Nossa Senhora da Ponte, erigida pelo fundador da cidade, a Igreja de Santa Ana, apesar das ampliações e reformas sofridas a partir do momento em que passou às mãos dos monges beneditinos, conservou o arcabouço da primitiva capela. Ao seu lado, os monges fizeram 




construir o mosteiro, cujas obras somente foram levadas a termo no princípio do século XVIII. Ambos foram edificados com taipa de pilão; os grandes beirais foram substituídos pela platibanda a partir das exigências do Código Municipal de Posturas de 1916, conservando-se, entretanto, até os dias de hoje a estrutura geral em sua feição primitiva. Desde 1978 o Mosteiro de São Bento e a Igreja de Santa Ana são tombados em nível estadual pelo Conselho de Defesa do Patrimônio Histórico, Arqueológico, Artístico e Turístico (Condephaat).

As fotografias relativas ao Convento de Santa Clara, de 1937, são menos numerosas se comparadas ao levantamento do Mosteiro de São Bento, restringindo-se a tomadas do interior da igreja, em que são registradas a nave e a capela-mor, destacando-se a pintura do teto desta última. Também do mesmo período é o levantamento fotográfico da Igreja de Santo Antônio, que se constitui de uma tomada externa do edifício (Figura 2) e, internamente, uma vista da talha do altar-mor.

O Recolhimento de Santa Clara, demolido na década de 1960, localizava-se na rua São Bento, logo abaixo do largo do Mosteiro. As obras da capela de taipa de pilão foram iniciadas por escravos pertencentes à 


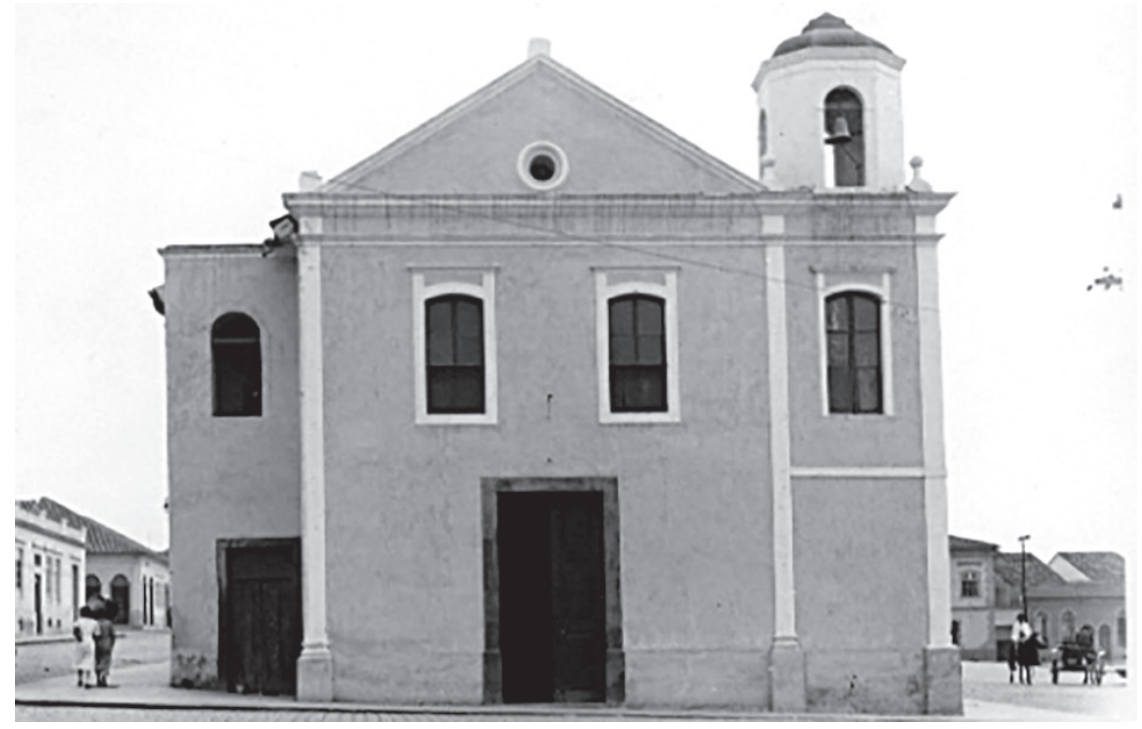

Irmandade de Nossa Senhora do Rosário dos Homens Pretos, à qual seria dedicada a construção, que, no entanto, só foi terminada por volta de 1770, após ter sido adquirida por Sarutaiá5. Já a construção do convento, anexo à capela, data do início do século XIX. Mário de Andrade relata a visita feita em 1937, dando conta de que, "apesar de um primeiro susto feminino das senhoras freiras, puderam ser vistos o convento de longe, a igreja em seu interior", e afirma ainda que "sua importância é relativa" (ANDRADE, 1981, p. 104).

A Igreja de Santo Antônio, de que se conseguiu "felizmente fotar a pobre fachada [...] e o seu altar-mor" (ANDRADE, 1981, p. 104), localizava-se no largo de mesmo nome, posteriormente chamado de Largo do Mercado, e é obra também do século XVIII, de taipa de pilão, tal como a capela do Recolhimento de Santa Clara. Foi construída por volta de 1750, quando o bispo de São Paulo autorizou a mudança da primitiva capela, situada na rua da Penha, para este local. Passou por reforma no início

5. Aluísio de Almeida assim narra o episódio: "Foi terminada pelo homem mais rico da cidade, coletor de impostos do Registro do Gado, Salvador de Oliveira Leme, o Sarutaiá, que morava quase em frente e comprara por $50 \$ 000$ as obras feitas desde antes de 1750 pela Irmandade de Nossa Senhora dos Homens Pretos, que gastavam em batuques as poucas esmolas recebidas. Santa Clara possuía uma pintura no forro, que segundo Mário de Andrade era da escola ituana de 1811 do Padre Jesuíno (do Monte Carmelo)" (PRESTES, 1999, p. 135). 
do século XX, quando foi edificada a torre sineira, tendo sido demolida nos anos 1950.

A Capela de Nossa Senhora Aparecida, situada no então Arraial de Aparecida, hoje distrito de Sorocaba que leva o nome de Aparecidinha, foi documentada em setembro de 1949 por Germano (Figura 3). Apenas duas fotografias foram encontradas: uma vista externa da edificação e a pintura do teto da sacristia, atribuída por Aluísio de Almeida ao pintor Inácio Joaquim Monteiro e datada dos anos 180o/1810.

O arraial de Aparecida, duas léguas a nordeste da cidade, foi principiado com a capela em 1785 e se compõe de uma rua que passa em frente ao templo, e respectivo largo (ALMEIDA, 1969, p. 116).

Assim narra Aluísio de Almeida o surgimento dessa capela, e continua: "A capela atual contém a torre e paredes da antiga, mas o arco-cruzeiro, que era de madeira pregada à taipa, se levantou com os tetos da capela-mor e do corpo da igreja" (ALMEIDA, 1969, p. 119). Tanto a capela quanto o traçado urbano do pequeno centro histórico de Aparecidinha foram tombados pelo Conselho Municipal de Defesa do Patrimônio, em meados dos anos 1990.

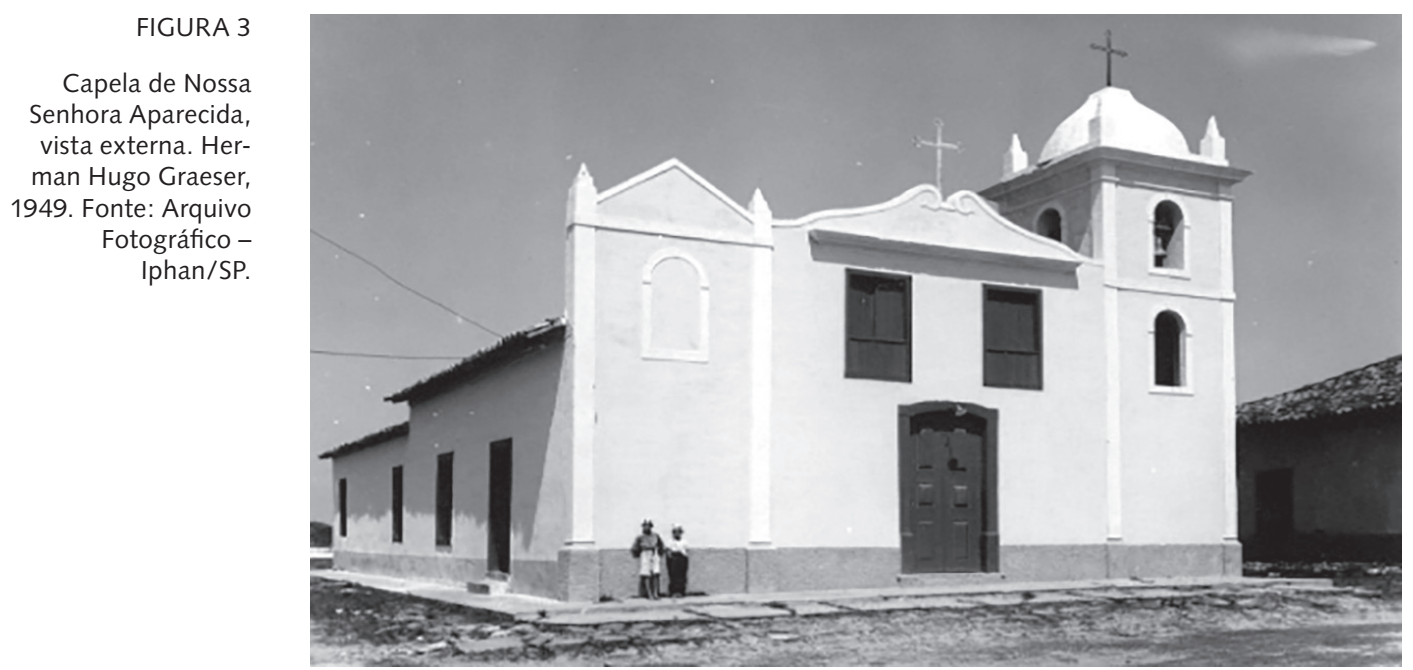


$\mathrm{Na}$ região conhecida como bairro de Itavuvu, então área rural da cidade, foram fotografadas por Germano a capela (Figura 4) e uma casa-grande. Em 1948 registrou-se não apenas uma vista geral do bairro e da capela como também as fachadas principal, lateral e dos fundos, além do interior da casa-grande de Itavuvu. Em setembro de 1949 foram executadas novas tomadas fotográficas da capela.

O bairro de Itavuvu - hoje inexistente com essa nomenclatura localizava-se nas proximidades da vila de Sorocaba, às margens do Rio Sorocaba, no lugar onde havia se dado o segundo núcleo de ocupação do território: a Vila de São Felipe, fundada em 1611. A casa-grande de Itavuvu, erguida por Manoel Joaquim de Barros, provavelmente no século XVIII, guardava algumas peculiaridades; ainda que se possa considerá-la herdeira da tradição bandeirista, a pureza formal nesse exemplar cede lugar a relevos que se destacam nas sobrevergas, com diversos desenhos - homens, navios, peixes. Ao que parece, o antigo alpendre, ou sala de fora, como era também denominado, foi fechado posteriormente, incorporado ao corpo da casa, construída de taipa de pilão (PRESTES, 1999, p. 101).

Outra residência rural que consta no inventário fotográfico do Iphan é a sede da Chácara do Quinzinho (Figura 5), que hoje em dia abriga as

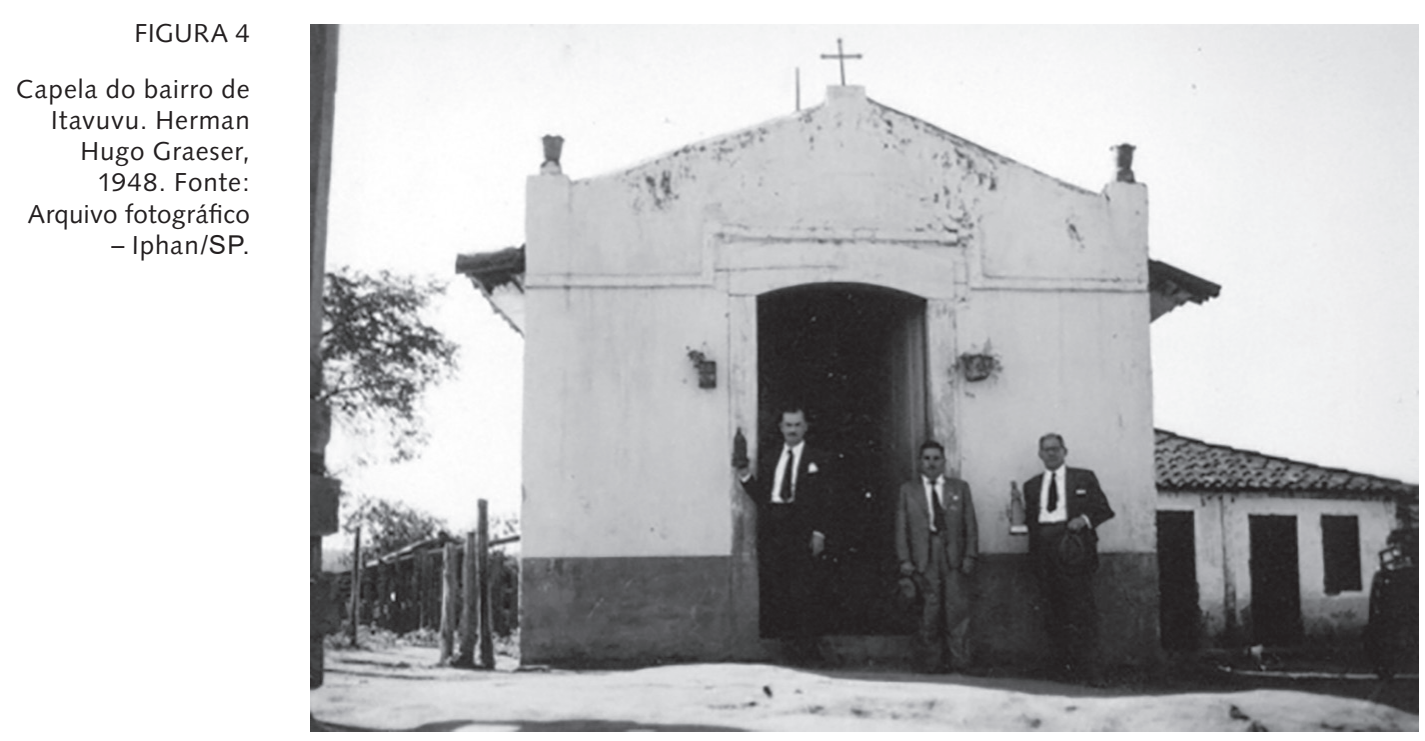




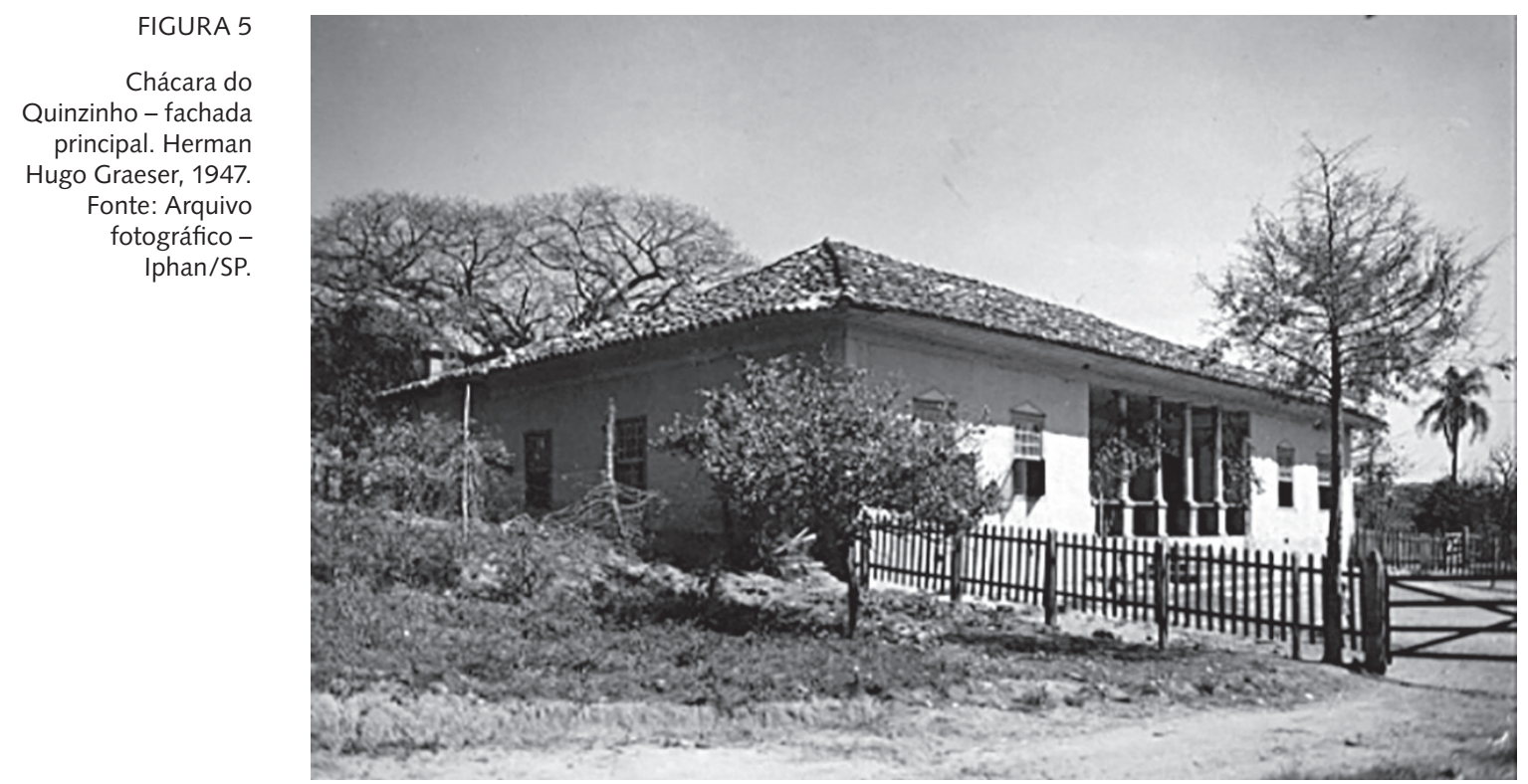

instalações do Museu Histórico Sorocabano e se encontra dentro do Parque Zoológico Municipal Quinzinho de Barros. As fotografias encontradas, datadas de 1947, são tanto das fachadas externas (frente e fundos) quanto dos cômodos no interior da casa, todas de autoria do fotógrafo Herman Hugo Graeser, o Germano.

Segundo informações de Luís Saia, a Chácara do Quinzinho estava entre os 12 exemplares de sedes de antigas fazendas caracterizadas como "solução arquitetônica típica para os fazendeiros mais abastados do século XVII" (SAIA, 1978, p. 62), embora se trate de exemplar edificado já nos setecentos.

Na descrição de Aluísio de Almeida (PRESTES, 1999, p. 190), "A casa é de taipa pilada; é a única de Sorocaba para o sul e uma das duas ou três de São Paulo que têm o alpendre (com o nome regional de pretório), com [...] colunas de madeira torneada, encaixado sob o telhado de quatro águas".

A última das edificações rurais de que se encontrou o registro fotográfico foi a Olaria Caracante (Figura 6), local historicamente atribuído à casa-grande de Baltazar Fernandes, bandeirante proveniente de Parnaíba e fundador da vila de Sorocaba. São também de Aluísio de Almeida as informações a respeito dessa edificação, demolida na década de 1960: 


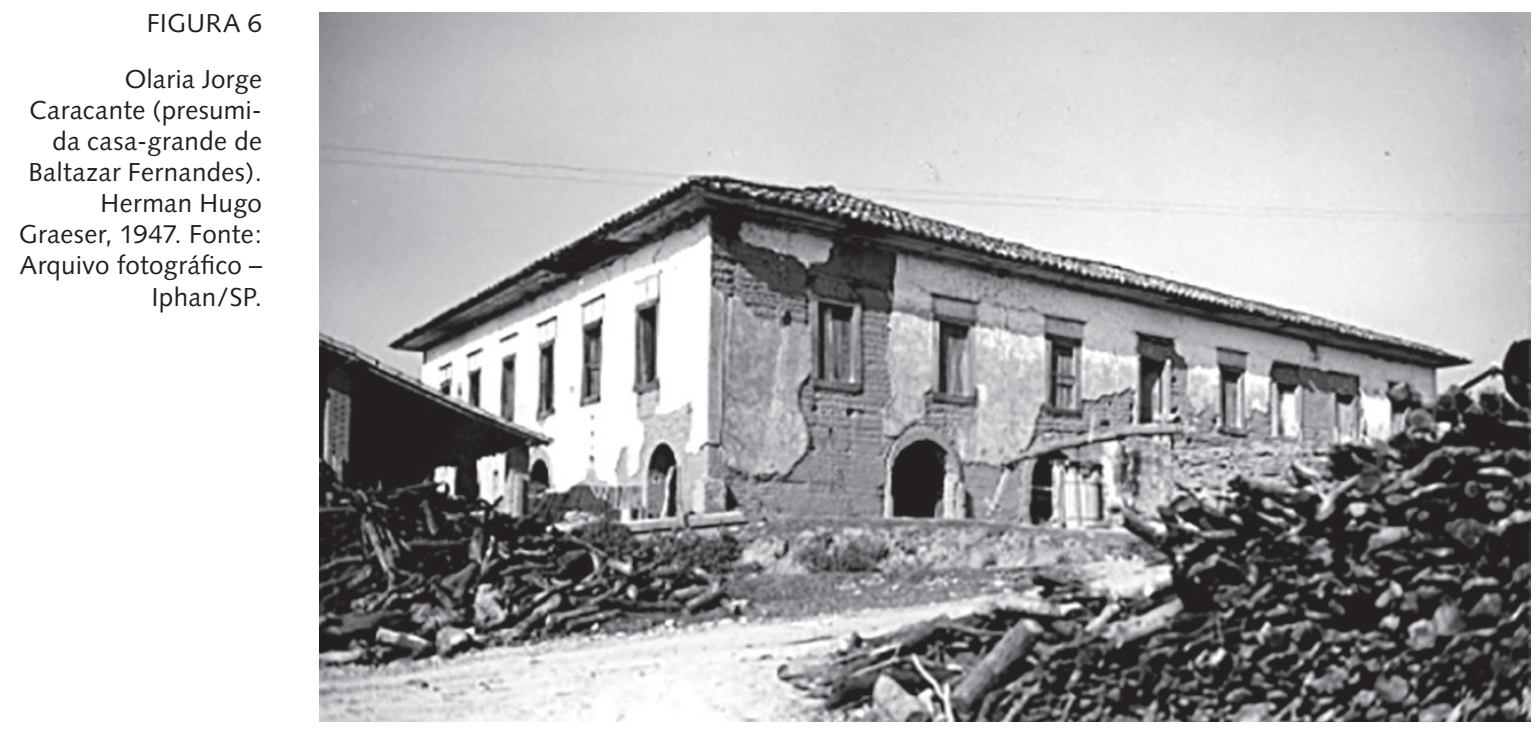

Quanto à tradição oral, resume-se nisto: aqui foi convento (não foi) e a primeira casa de Sorocaba (foi). Atualmente é tapera. Seu proprietário, sr. Caracante, faz no salão obtido com a derrubada de paredes internas depósito de madeira, o porão é onde se alinham tijolos da sua olaria. Não havendo possibilidade para documentar as transformações havidas, resta apelar para a arquitetura. O competente engenheiro sr. Luís Saia (do Serviço do Patrimônio Histórico e Artístico Nacional) julga que a casa é certamente do século 18 e possivelmente do século 17 sem reforma substancial (PRESTES, 1999, p. 104).

Se comparada à tradição bandeirista, a casa-grande de Baltazar Fernandes apresentava inúmeros aspectos que fugiam àquele modelo proposto por Luís Saia e outros historiadores da arquitetura paulista: a planta era em L e não retangular, como o usual (podendo indicar posterior acréscimo); o madeiramento do telhado era com tesouras, embora a técnica construtiva adotada fosse a taipa; havia, ademais, porões abertos com arcos de alvenaria de tijolos. Todos esses elementos foram documentados através das fotografias, que incluíam ainda o registro de um oratório de madeira 
policromada, transferido para o Sítio Santo Antônio na década de 1940 e, posteriormente, para a sede paulista do Iphan.

Das várias residências urbanas inventariadas pelos técnicos do Patrimônio em Sorocaba, apenas uma mereceu registro mais detido: o exemplar situado na Rua Nogueira Padilha, número 106, que pertenceu ao capitão-mor José de Barros Lima, datada provavelmente de 1765 . Foram fotografadas por Germano, em 1947, vistas internas e externas, bem como alguns detalhes construtivos e decorativos desse imóvel - já demolido, tal como os outros exemplares de residências urbanas levantados pelo Patrimônio Nacional na ocasião.

Finalmente, no tocante ao material pesquisado na $9^{\text {a }}$ S.R./Iphan, a documentação da Fazenda Ipanema parece ter ocupado o maior interesse entre os levantamentos feitos - sendo o bem com o número de fotografias mais significativo, seja de inventário ou documentação, como nos anos de 1948, 1965 (a partir desse ano, já tombada como patrimônio histórico nacional), 1974/75 e 1977/78, seja através do registro das obras de restauro empreendidas no local, desde 1969 até 1971.

O conjunto formado pelos remanescentes da Real Fábrica de Ferro São João de Ipanema foi o único exemplar de arquitetura de Sorocaba ${ }^{6}$ incluído em um dos Livros de Tombo do Iphan. A inscrição, datada de 1964, seguindo a amargurada recomendação de Mário de Andrade, deu-se exclusivamente no Livro Histórico, por se tratar de

Remanescentes de arqueologia industrial do primeiro complexo funcionante para exploração e fabricação do ferro no Brasil. [...] Estas instalações funcionaram até o final do século XIX, produzindo grades, equipamento agrícola e armas brancas (IPHAN, Arquivo Noronha Santos - Processo 0727-T-64).

A análise do processo de tombamento de Ipanema, sob a guarda do Arquivo Noronha Santos 7 , não deixa claro qual o perímetro de tombamento, posto

6. Embora a Fazenda Ipanema pertença atualmente ao município de Iperó e não mais a Sorocaba, o tombamento deu-se quando o bem ainda fazia parte do município de Sorocaba.

7. Tombamento da Real Fábrica de Ferro São João do Ipanema (Iperó, SP). Número do processo: 0727-T-64. O Arquivo Noronha Santos é o depositário dos processos de tombamento das três primeiras décadas de atuação do Iphan (1937 a 1968), período em que foram realizados os trabalhos de levantamento, tombamento e restauração relativos à Fazenda Ipanema e ao município de Sorocaba. A consulta realizou-se em julho de 2004. 


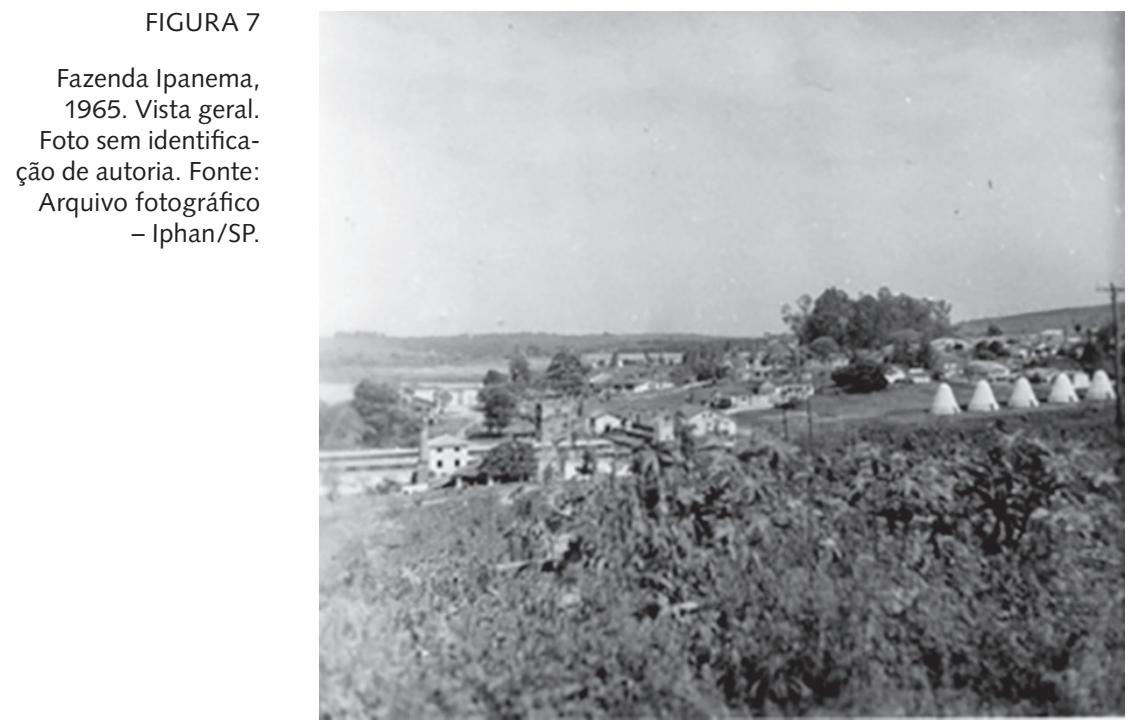

que, após vistoria às instalações, o chefe da regional paulista do Iphan, o arquiteto Luís Saia, recomendava apenas o tombamento de alguns exemplares isolados, como se pode aferir em seu relatório:

O tombamento do conjunto parece a esta chefia desaconselhável em virtude da desunidade do atual aglomerado arquitetônico, e também porque tal iniciativa viria certamente conflitar com a situação vigente de aproveitamento da fazenda em questão para fins de aprendizado agrícola (Carta de Luis Saia encaminhada a Rodrigo Melo Franco de Andrade em 1949. IPHAN, Arquivo Noronha Santos - Processo 0727-T-64).

Entretanto, a indicação contida no referido processo dá a entender que foi tombado todo o conjunto fabril, situado no local onde Afonso Sardinha havia descoberto minério de ferro ainda nos anos 1590, e que inclui os fornos e forjas para ferro, algumas estruturas de apoio ainda existentes, como é o caso da serraria, a casa-sede da Fazenda e a pequena vila de Varnhagen, com casas de diversas tipologias e tamanhos.

Tendo em vista que a exploração do minério de ferro se deu, frustradas as iniciativas anteriores, somente após a vinda da família real para o Brasil, em 1810, quando o governador-geral da província 


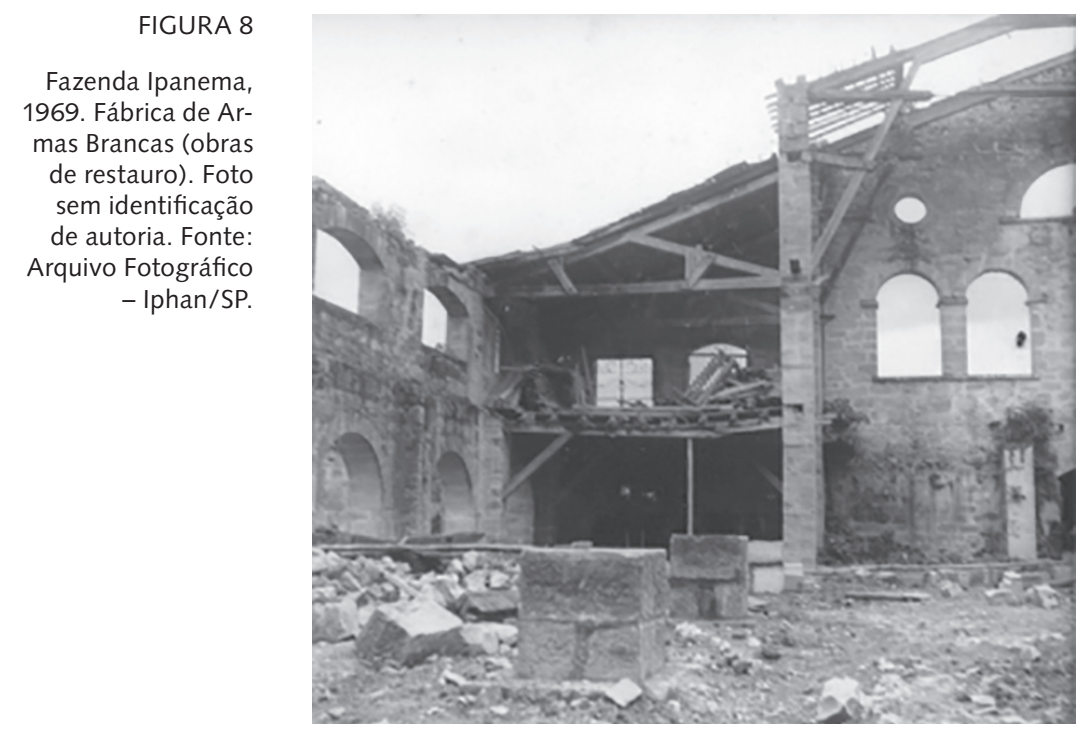

chega a Sorocaba acompanhado pelo químico ituano João Manso, para instalar a Fábrica de Ferro São João d'Ypanema, grande parte de suas instalações é da primeira metade do século XIX, como é o caso dos altos-fornos, construídos com a chegada de Varnhagen e de técnicos suecos. Predomina a técnica construtiva da alvenaria de pedra, tendo-se o registro da participação de mestres de cantaria vindos de Santos para as obras do local (PRESTES, 1999, p. 153). A casa-sede, inicialmente apenas com um pavimento, é erguida em taipa de pilão sobre alicerce de pedra. Com paredes internas de pau-a-pique, a capela se destaca do corpo principal da casa, em meia-lua, abrindo-se para o alpendre. $\mathrm{O}$ segundo andar foi construído somente nos anos 1850, para hospedar o imperador Dom Pedro II, em visita à Fábrica.

Através das fotografias analisadas não se pôde inferir o alcance das obras realizadas em Ipanema pelos técnicos do Patrimônio na década de 1960/70; a documentação fotográfica restringe-se à recuperação da Fábrica de Armas

8. A biblioteca da $9^{\text {a }} \mathrm{SR} / \mathrm{Iphan}$, provavelmente, deve conter dados mais precisos não só a respeito das obras em Ipanema, mas também no que diz respeito às outras edificações inventariadas pelo Iphan em Sorocaba. Não foi possível, no entanto, o acesso a esse acervo na ocasião do desenvolvimento da pesquisa. 
Brancas (Figuras 8 e 9), que se encontrava com a fachada posterior e $o$ telhado bastante arruinados, e na qual se previa, na ocasião das obras, a instalação do Museu do Ferro.

A julgar pela análise das fotografias e também pelo que se vê atualmente no local, o procedimento de restauro adotado foi o refazimento total da área arruinada, com materiais idênticos aos originais, seguindo - por analogia - as formas ainda existentes, seja na própria fachada arruinada, seja na fachada frontal.

Em que pese a impossibilidade de acessar o caderno de obras e outros documentos arquivados na $9^{a}$ SR/Iphan, é importante frisar mais uma vez o papel que as imagens fotográficas têm para a compreensão dos procedimentos executados sobre o bem tombado, tendo em vista, muitas vezes, a ausência de um projeto de restauro arquitetônico propriamente dito (GONÇALVES, 2007, p. 202). Dessa forma, a documentação fotográfica assume o caráter de principal meio de registro daquilo que foi executado

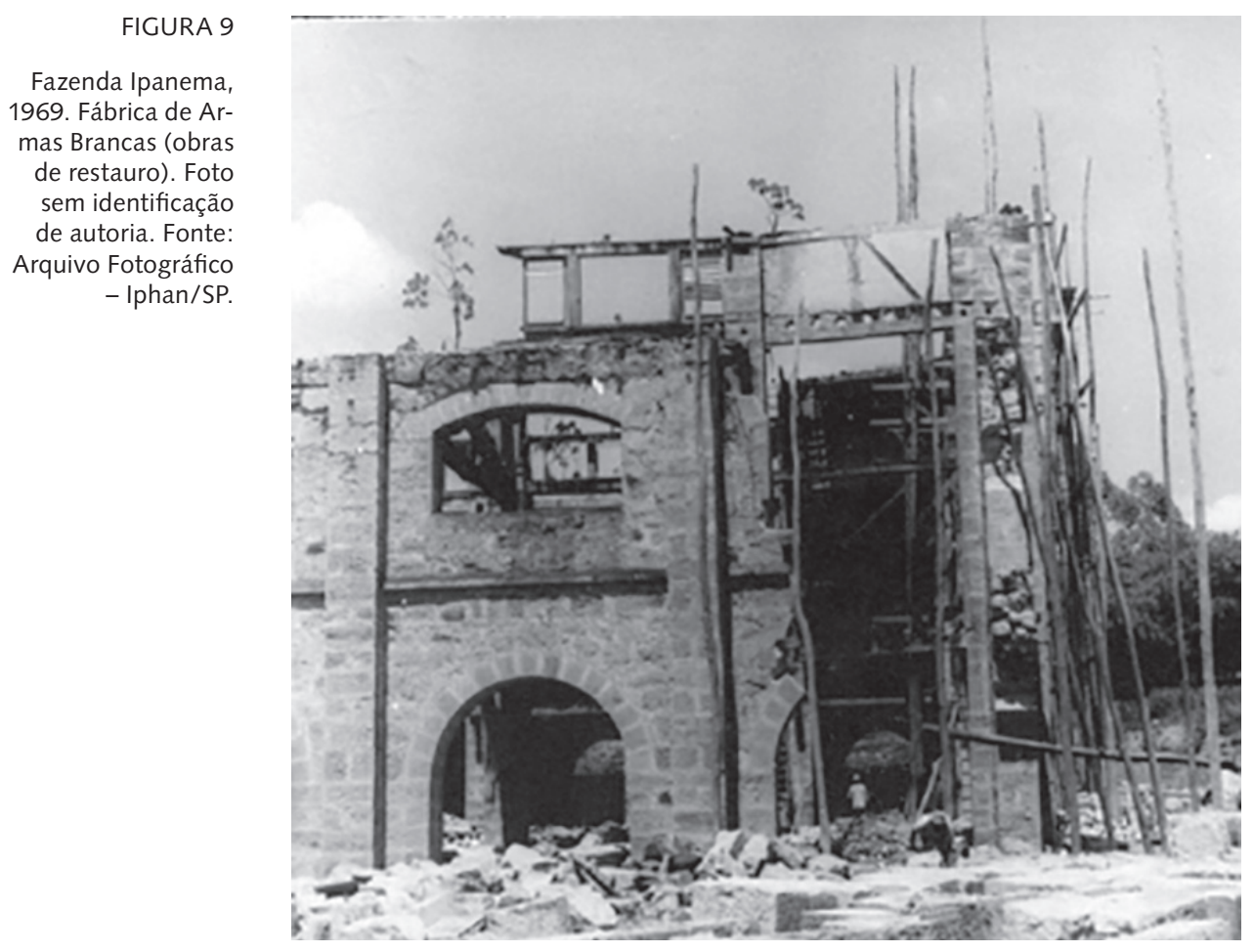


durante as obras, bem como da situação encontrada anteriormente às mesmas e a face final do monumento restaurado.

A documentação fotográfica também se tornou imprescindível para fins de estudo das obras de conservação e restauração propostas pelo SPHAN, bem como para a verificação dos trabalhos executados e, ainda, instrumentos de consulta e pesquisa por parte dos técnicos do Serviço e pesquisadores do patrimônio cultural brasileiro (FONSECA; CERQUEIRA, 2008, p. 24).

A Fazenda Ipanema, nos anos 1960/70, estava sob a administração do Ministério da Agricultura, que ali implantara um Centro de Treinamento Rural (CENTRI), e planejava a expansão das atividades, criando o Centro Nacional de Engenharia Agrícola (CENEA), cujo núcleo principal de atividade, além da produção de fertilizantes e do desenvolvimento de máquinas agrícolas, seria a formação de pilotos e equipes de terra para o uso de aviões na semeadura e aplicação de agrotóxicos. O projeto para a implantação em Ipanema do CENEA, que incluía ademais a criação do Museu do Ferro, foi encomendado ao arquiteto Paulo Mendes da Rocha, que contou com a colaboração de Antonio Luiz Dias de Andrade (técnico do Iphan), Roberto Leme Ferreira e César Luz Mazzacoratti (CJ Arquitetura, 1978, p. 68). Conforme descrito no memorial do projeto:

Verifica-se em Ipanema que parte das instalações que abrigam as dependências do Centro de Treinamento Rural se utilizam das primitivas construções remanescentes da antiga Fábrica de Ferro adaptadas para tal fim, sendo as áreas existentes entre essas mesmas edificações também ocupadas por construções posteriores, sem que obedeçam a algum critério ou planejamento, ocorrendo mesmo certa inoperância de circulação racional entre os diversos setores do CENTRI (C) Arquitetura, 1978, p. 69).

A falta de racionalidade na circulação e o alto valor dos monumentos de Ipanema levaram a equipe de projeto a propor primeiramente um plano piloto, 
[...] garantindo uma nova organização do entorno paisagístico daqueles monumentos, que possa restaurar sua primitiva escala de implantação e situar as novas edificações de maneira que suas ampliações futuras, presumíveis, não voltem a perturbar necessariamente aquelas áreas, adaptando também o sistema viário geral interno para se obter a melhor eficiência e vantagens visuais (CJ Arquitetura, 1978, p. 69-70).

A execução desse projeto, entretanto, não foi levada a cabo, e, não obstante as obras de restauro realizadas em fins dos anos 1960 e início de 1970, a conservação geral do sítio, atualmente sob a responsabilidade do Instituto Brasileiro do Meio Ambiente e dos Recursos Naturais Renováveis (Ibama) por se tratar de uma Floresta Nacional", é bastante precária. Não foram executadas obras de conservação e manutenção posteriores, ou, ao menos, estas não se encontram documentadas no acervo fotográfico do Iphan/SP e tampouco no processo de tombamento do bem. Desse modo, adiante da ausência de consertos e reparos de pequeno porte, mas essenciais para a garantia de boas condições dos edifícios, várias construções estão totalmente arruinadas e outras necessitam de reparos de grande monta.

\section{O IPHAN E SOROCABA: ALGUMAS CONSIDERAÇÕES}

De 1937 a 1968, a instituição do patrimônio em São Paulo foi atribuição exclusiva do poder federal. Dessa atuação resultou o reconhecimento de edificações remanescentes do povoamento do litoral, as casas rurais bandeiristas, sedes de antigas fazendas de café, capelas e igrejas dos seiscentos, como representantes máximos do passado paulista (RODRIGUES, 2000, p. 37).

Mediante análise da documentação fotográfica realizada pelo Iphan na região de Sorocaba, pôde-se tirar algumas conclusões sobre a atuação do órgão de preservação federal no município. Em primeiro lugar, vale retomar os escritos de Luís Saia, que indicava em seu texto "Quadro geral dos monumentos paulistas" a metodologia a ser adotada nos trabalhos de documentação:

9. Decreto n. 530, de 20 de maio de 1992. 
Dos dois caminhos disponíveis para intentar esta pesquisa [sobre os monumentos paulistas], preferimos estabelecer, como hipótese de trabalho, uma procura das teses que caracterizam a formação paulista, para o que procuramos determinar os sucessivos períodos da colonização na sua expressão regional (SAIA, 1978, p. 25, grifo nosso).

Assim sendo, se o arquiteto afirmava a inoperância de modelos predeterminados com validade para todo o território nacional, calcados assim em realidade estranha à região, o movimento que procura fazer é o de estabelecer um modelo que fosse válido para o caso paulista. Ao construir esse modelo, procurando as teses que caracterizassem a formação paulista, não deixou espaço para as especificidades de cada sítio visitado, os quais deveriam se encaixar nesse quadro geral preestabelecido, tal como no caso dos monumentos nacionais de outros estados - alvo das críticas de Saia.

A valorização dos bens encontrados se dava, então, na exata medida em que se aproximassem ou se afastassem daquele modelo idealizado, como no exemplo da Chácara do Quinzinho ou no da residência da Rua Nogueira Padilha, ambas citadas por Saia em seu Morada paulista (SAIA, 1978, p. 86 e 174). Tanto em relação à Chácara do Quinzinho quanto à casa da Nogueira Padilha, ambas construções setecentistas, o provável desinteresse pelo tombamento se deu em função do afastamento (tanto temporal quanto tipológico) do modelo idealizado de casa seiscentista do bandeirante paulista. Segundo o autor, por se tratar de exemplares tardios, guardavam certas deformações e mesmo a marca da degeneração imposta ao estilo quando em decadência, o que pode ser percebido pelo seguinte trecho:

Basta a injunção de um costume estranho para que a residência da classe dominante abandone aquele sentido de solução purista que manteve nos exemplares do século XVII, e passe a aceitar acréscimos que desnaturam o partido que tão bem respondera ao programa paulista. Na planta que perde a simplicidade e limpeza presentes nos exemplares mais antigos; no esquema construtivo, que passa a acusar soluções arranjadas e desconformes. E assume um garbo elegante, como na casa de Sorocaba [...] (SAIA, 1978, p. 135). 
No que se refere às igrejas e capelas - tanto urbanas quanto rurais -, parece que o critério de valoração era semelhante ao adotado para a arquitetura civil: a proximidade com os modelos estabelecidos da arquitetura religiosa do período bandeirista. Como os exemplares encontrados em Sorocaba encontravam-se já alterados em suas feições originárias pelos padrões estéticos do início do século XX ou mesmo acrescidos de novas partes construídas nesse mesmo período, não houve interesse pelo tombamento. Deve-se acrescentar ainda, que, dado que algumas capelas já haviam sido protegidas por essa determinação legal em território paulista, e diante da necessidade de escolher criteriosamente os bens a serem arrolados nos livros de tombo em virtude dos poucos recursos existentes na instituição, a possibilidade de tutela por parte do governo federal das igrejas e capelas de Sorocaba ficou excluída.

Certamente não se encontraria em Sorocaba, como no restante do estado, a pujança e riqueza artística de outras regiões do país, que pudesse atender ao critério de excepcionalidade exigido pelo Decreto-lei n. 25/37. Também, sob os olhos dos técnicos do Patrimônio, a cidade não foi palco de grandes eventos históricos, seja do país ou regionais, que fossem "particularmente expressivos ou característicos dos aspectos e das etapas principais da formação social do Brasil e da evolução peculiar dos diversos elementos que constituíram a população brasileira" (ANDRADE, 1981, p. 29). Daí decorre a dificuldade de encontrar, entre os bens inventariados na região, exemplares que pudessem ser tombados em nível federal, exceção feita à Fazenda Ipanema, como já mencionado anteriormente.

Tanto Luís Saia quanto outros técnicos e colaboradores do Iphan estavam, desde o primeiro momento de buscas na região de Sorocaba, com o olhar direcionado a uma tipologia bastante específica de bens arquitetônicos - as edificações bandeiristas.

Reforça-se aqui a análise feita por COSTA (2016), segundo a qual as fotografias denunciam um olhar preestabelecido, que buscava na realidade concreta algo de específico, e não se abria para analisar objetivamente o que se apresentava ao olhar, aceitando valorar bens distintos daqueles que se buscavam.

O modelo idealizado da construção bandeirista - alvo das pesquisas do Patrimônio Nacional - não foi encontrado na cidade, ou, se foi, os 
representantes locais traziam em si elementos que os desabilitavam como postulantes à proteção federal através do tombamento. O desconhecimento da realidade local e das peculiaridades a envolver o sítio visitado dificultaram o reconhecimento do valor dos monumentos históricos sorocabanos, impedindo, assim, sua possível preservação através do tombamento.

Ainda outra colocação a fazer refere-se ao alvo das pesquisas feitas pelo Iphan em Sorocaba. Todas as obras documentadas eram do período colonial, não excedendo a primeira metade do século XIX. Isso pode ser notado a partir da análise do acervo fotográfico relativo a Sorocaba, no qual se verifica a hegemonia absoluta das edificações, em face de alguns esporádicos registros de bens móveis ou bens móveis integrados. Entre os bens arquitetônicos fotografados, acham-se exclusivamente imóveis do século XVII ao primeiro quartel do século XIX, destacando-se as "capelas e casas-grandes históricas" (ANDRADE, 1981, p. 71), conforme indicado por Mário de Andrade.

Ainda que Sorocaba tenha sido fundada por bandeirantes, ciclo histórico-econômico privilegiado pelos arquitetos do Patrimônio em terras paulistas, a vila logo assume novos rumos, dedicando-se a sediar as feiras de muares, caracterizando-se como um centro voltado basicamente para o comércio. Desse modo, engenhos e fazendas, ainda que existentes no local, não possuíam a relevância manifesta nas vilas vizinhas, como Itu e Piracicaba; ao contrário, a população local dividia-se entre pequenos sítios nos arrabaldes e as atividades urbanas ligadas ao comércio de animais, daí a especificidade na forma de ocupação do território e nas soluções arquitetônicas adotadas na cidade.

Pode-se então afirmar que aquelas etapas de formação da realidade regional - determinadas pelos funcionários da regional paulista do órgão federal de preservação - não abriam espaço para a manifestação das peculiaridades locais, envolvendo, desse modo, as cidades numa trama histórica mais ampla, em que se destacavam apenas as etapas de povoamento, dentre as quais o ciclo do tropeirismo, fundamental em Sorocaba, não figurava ainda como marco importante ${ }^{10}$.

10. O tropeirismo passou a ser alvo das preocupações junto aos órgãos de preservação somente a partir da década de 1980, ocasião em que se desenvolveu o projeto Caminho das Tropas, que tinha como objetivo a identificação e a valorização dos remanescentes da cultura tropeira ao longo do 
Ademais, foram desconsiderados pelos técnicos do patrimônio nacional os sobrados construídos nos últimos quartéis do século XIX, período de grande expansão na mancha urbana e intensa ocupação dos vazios urbanos na região central de Sorocaba, anteriormente destinados às pastagens para o gado em tempos de feira. Ignoraram-se, também, as instalações industriais do mesmo período, marcos fundamentais não apenas na paisagem do local, mas na própria identidade dos sorocabanos. Durante as duas décadas em que foram feitas as fotografias de inventário, Sorocaba ainda era conhecida (e reconhecida por seus habitantes) como "Manchester Paulista", traço absolutamente não cogitado na apreciação do Iphan, que, entretanto, tem como único monumento sorocabano em um de seus livros de tombo exatamente um representante da arqueologia industrial, a Fazenda Ipanema.

Para finalizar esta breve análise, ressalta-se a afirmação de Costa (2015, p. 88-89):

Assim, ao retomar o lugar do Arquivo Fotográfico do IPHAN e, finalmente, a visualidade que ele organiza como representação e memória do Patrimônio Histórico e Artístico Nacional, pode-se compreendê-lo não como um resultado da reunião de documentos visuais que representam um conjunto de monumentos diversos, distribuídos no espaço do território brasileiro, mas sim como uma topografia simbólica, formada através de intenções e protocolos, emoldurados a partir da escolha por determinados objetos.

Essa topografia simbólica estabelecida com os levantamentos fotográficos da instituição, que define visualmente aquilo que tem valor e, por exclusão, aquilo que não tem, reforça a ideia de construção cultural inerente ao corpo patrimonial, que é sempre, e em qualquer localidade, fruto de escolhas - do que é eleito e do que não é. Tais escolhas são inevitáveis e, quando analisadas cronologicamente por meio do próprio acervo fotográfico, criam um roteiro de conceitos e retraçam, dessa forma, a própria história da noção de patrimônio e seu devir no tempo.

antigo Caminho do Viamão. O projeto envolvia o Condephaat, as regionais de São Paulo, Paraná e Rio Grande do Sul do Iphan e as Secretarias de Cultura desses mesmos estados, porém não teve continuidade. As informações estão em: RODRIGUES, 2000, p. 142. 
Uma última observação a ser feita com relação ao acervo fotográfico referente a Sorocaba é sua importância como registro de monumentos que desapareceram na sua quase totalidade. Quando se fala em patrimônio arquitetônico, sabe-se que a vivência do espaço é uma experiência insubstituível e que qualquer documentação, por mais extensa e completa que seja, jamais dá conta da complexidade que é o vivenciar uma dada espacialidade. Sendo assim, lamenta-se profundamente o fato de que esses bens inventariados pelo Patrimônio tenham sido destruídos, pois a premissa básica para os bens arquitetônicos é sua manutenção e uso, para que se possa fruí-lo. Porém, na ausência dessas edificações, a preservação iconográfica, por meio das fotografias arquivadas na $9^{a}$ SR/Iphan, é o registro desse pedaço de memória urbana que se perdeu e mostra fragmentos de uma Sorocaba desaparecida. Mais uma razão para a cuidadosa conservação e gestão desse acervo, ele também um patrimônio nacional.

\section{REFERÊNCIAS}

ALMEIDA, Aluísio. Casas do século 18 e 19 em Sorocaba. Revista Serviço do Patrimônio do Histórico e Artístico Nacional, Rio de Janeiro, n. 9, p. 347-368, 1945.

História de Sorocaba. Sorocaba: Instituto Histórico, Geográfico e Genealógico de Sorocaba, 1969.

ANDRADE, Mário. Mário de Andrade: cartas de trabalho. Correspondência com Rodrigo Melo Franco de Andrade, 1936-1945. Brasília: Fundação Nacional Pró-Memória, 1981.

ANDRADE, Rodrigo M. F. de. Rodrigo e o SPHAN: coletânea de textos sobre patrimônio cultural. Rio de Janeiro: Fundação Nacional Pró-Memória, 1987.

CAVALCANTI, Lauro (Org.). Modernistas na repartição. Rio de Janeiro: UFRJ/Iphan, 1993.

CJ Arquitetura - Patrimônio Cultural de São Paulo, n. 19, p. 68-72, 1978

COSTA, Eduardo. Arquivo, poder, memória: Herman Hugo Graeser e o arquivo fotográfico do Iphan. 2015. 459 f. Tese (Doutorado em Política, Memória e Cidades) - Instituto de Filosofia e Ciências Humanas da Universidade de Campinas, Campinas, 2015.

. Da fotografia à cultura visual: arquivo fotográfico e práticas de preservação do Iphan. Anais do Museu Paulista, São Paulo, v. 24, n. 3, p. 19-43, set.-dez. 2016.

FONSECA, Brenda Coelho; CERQUEIRA, Telma Soares. Mapeamento preliminar das atividades dos fotógrafos no IPHAN (1937-1987). In: Cadernos de Pesquisa e Documentação do IPHAN: a fotografia na preservação do patrimônio cultural: uma abordagem preliminar. Rio de Janeiro: Copedoc/Iphan, p. 13-65, 2008.

GONÇALVES, Cristiane Souza. Metodologia para a restauração arquitetônica: a experiência do Serviço do Patrimônio Histórico e Artístico Nacional em São Paulo, 1937-1975. Dissertação 
(Mestrado em Teoria e História da Arquitetura) - Faculdade de Arquitetura e Urbanismo da Universidade de São Paulo, São Paulo, 2004.

Restauração arquitetônica: a experiência do SPHAN em São Paulo, 1937-1975. São Paulo: Annablume/Fapesp, 2007.

IPHAN (Brasil). Cartas patrimoniais. 2. ed. Rio de Janeiro: Iphan, 2000.

MENESES, Ulpiano Toledo Bezerra de. Fontes visuais, cultura visual, história visual: balanço provisório, propostas cautelares. Revista Brasileira de História, São Paulo, v. 23, n. 45, p. 11-36, 2003.

MICELI, Sergio. SPAHN: refrigério da cultura oficial. Revista do Patrimônio Histórico e Artístico Nacional, Rio de Janeiro: SPHAN/Pró-Memória, n. 22, p. 44-47, 1987.

MOTTA, Lia. A SPHAN e o IBPC, política de inventário e cadastro. Anais do I Congresso Latino-Americano sobre a Cultura Arquitetônica e Urbanística: perspectivas para a sua preservação. Porto Alegre: SMC, 1992. p. 27.

PRESTES, Lucinda Ferreira. A Vila Tropeira de Nossa Senhora da Ponte de Sorocaba: aspectos socioeconômicos e arquitetura das classes dominantes (1750-1888). São Paulo: ProEditores, 1999.

RODRIGUES, Marly. Imagens do passado: a instituição do patrimônio em São Paulo, 1969-1987. São Paulo: Unesp/Imprensa Oficial/Condephaat/Fapesp, 2000.

RUBINO, Silvana. A memória de Mário. Revista do Patrimônio - Mário de Andrade, Rio de Janeiro: Iphan, n. 30, p. 139-154, 2002.

. O mapa do Brasil passado. Revista do Patrimônio - Cidadania, Rio de Janeiro: Iphan, n. 24, p. 97-105, 1996

. As fachadas da história: os antecedentes, a criação e os trabalhos do Serviço do Patrimônio Histórico e Artístico Nacional, 1937-1968. 1991. Dissertação (Mestrado em Antropologia Cultural) - Instituto de Filosofia e Ciências Humanas da Universidade Estadual de Campinas, Campinas, 1991.

SAIA, Luís. Morada paulista. São Paulo: Perspectiva, 1978.

. Notas sobre a arquitetura rural paulista do segundo século. Revista do Iphan, v. 8, p. 217-224, 1947 